\title{
The interface between old age psychiatry and the law
}

\author{
Brian Murray \& Robin Jacoby
}

This article aims to provide a practical overview concentrating on civil legal aspects of psychiatric care for the elderly. We limit ourselves to English law (which also has jurisdiction in Wales; Scottish and Northern Irish law may be similar, but not identical). Civil law can, in turn, be divided into statute law (legislation provided by Parliament) and common law (the UK, unlike some European countries, has a strong tradition of law based on previous rulings by judges).

We assume that the reader has a reasonable working knowledge of the Mental Health Act (MHA) 1983 and issues related to capacity. However, work in old age psychiatry regularly means encountering problems related to dementia, capacity, driving, long-term care and financial matters that require a knowledge of the law over and above that of the general adult psychiatrist.

\section{Capacity}

Capacity (or competence) is a person's ability to make a particular decision at a specific time or in a specific situation. In other words, capacity is not something we carry around with us from one decision to the next, but it has to be re-evaluated for each important decision. It is worth pointing out that the MHA 1983 is based not on capacity, but purely on diagnosis: in fact, a patient detained under the MHA is still regarded as having (limited) rights to make decisions on other matters (Fazel, 2002).

A patient with dementia may forget a decision after it has been made, but as long as it can be demonstrated that the decision was reached through the process above, it may still be valid. However, in such a situation it is advisable to make sure that the patient would make the same choice if presented with the same facts on a different occasion (Arie, 1996).

Many referrals to old age psychiatrists are from medical colleagues requesting an assessment of capacity. While old age psychiatrists may be regarded as specialists in this field, assessment of capacity should not be a skill exclusive to psychiatrists. Consent for medical or surgical procedures is best obtained by someone aware of all the issues and complications, and ideally by the doctor performing the procedure in question.

If a patient with physical illness lacks capacity to agree or disagree to a particular course of treatment, then the doctor should proceed only if it is in the patient's best interests (usually meaning to prevent death or significant deterioration in health). Treatment should be the minimum possible to prevent death or irreparable damage, and should be provided for only so long as the situation demands. Guidance is offered by the British Medical Association \& the Law Society (1995) and the Department of Health (2001). Good documentation with comment on each of the tests for capacity is essential (see Box 1).

Although these rules appear strict, in practice UK judges are sympathetic to the complexities of everyday clinical practice and doctors have been allowed much leeway (debatably, too much). In urgent situations such as accident and emergency referrals, it is safer to assume lack of capacity when in doubt. The high level of liaison work involved in old age psychiatry affords us an opportunity to emphasise these points to our medical colleagues,

Brian Murray is a specialist registrar training in old age and general adult psychiatry at the Churchill Hospital, Oxford. He has conducted research on Ginkgo biloba, a herbal remedy used in dementia. Robin Jacoby is Professor of Old Age Psychiatry at the Warneford Hospital (University of Oxford, Department of Psychiatry, The Warneford Hospital, Oxford OX3 7JX, UK). He was a consultant psychiatrist at the Bethlem Royal and Maudsley Hospitals from 1983 to 1993. 


\section{Box 1 Assessment of capacity}

The person must demonstrate an ability to both understand and retain the necessary information long enough to make a judgement. Note that this puts the onus on the doctor to provide all the relevant information to the patient. Limiting information simply because it seems to be in accordance with a substantial body of contemporary medical opinion (the Bolam standard; from Bolam v Governors of Friern Hospital, 1957) may no longer be enough

The person should show an ability to weigh up the pros and cons of his ot her choice

He or she should be under no undue pressure

who are frequently affected by a fear of litigation. For example, many non-psychiatrists erroneously believe that the MHA may be used to permit treatment for a physical illness if the patient lacks capacity to consent. The MHA may, however, be used only for mental disorder.

\section{Issues relating to admission and management}

\section{Bournewood}

Although the original Bournewood case related to a man (H.L.) with learning disability ( $R v$ Bournewood Community Mental Health NHS Trust, ex parte L, 1998), it had profound implications for old age psychiatry because it challenged the practice of informally admitting patients who did not object, but who lacked capacity to consent to admission. Any old age psychiatry ward will have a significant number of people with dementia who would fall into this category.

The Bournewood case (Box 2) caused much debate among psychiatrists. The differing accounts of the case make comment difficult, but many felt that the matter had been mismanaged and that there was a danger of 'bad case makes bad law'. Many supported a pragmatic approach to informal detention, arguing that forcing patients with dementia through a process of compulsory detention was unnecessary and distressing for all parties. It was also pointed out that a change in practice would cause a huge drain on clinical resources and those of the MHA Commission. On the other hand, many felt that the Bournewood case had exposed an important gap in mental health legislation, which deprived vulnerable patients of certain rights under the MHA. An audit carried out at the time showed that the majority of old age psychiatrists seemed to share this view, but, despite an initial increase in admissions under the MHA, practice soon returned to normal after the ruling of the House of Lords (Kearney \& Treloar, 2000).

There is nothing to stop an informal admission similar to that of H.L.'s being challenged again, but this time under Articles 5 and 6 of the Human Rights Act 1998. These guarantee, respectively, rights to liberty and a fair trial (and the assumption of a right to appeal). It is difficult to predict what the outcome of such a court case would be as the Bournewood matter was resolved not according to the letter of mental health law, but by reference to its guiding principles. This introduces a convenient measure of subjectivity to any ruling.

It was hoped that proposed reforms to the MHA might clarify admission decisions by taking into account the patient's capacity, but it remains to be seen if these ideas emerge unscathed in the final legislation.

In the meantime, good practice would entail consultation with relatives and carers about decisions to admit informally, with use of the MHA

\section{Box 2 Outline of the Bournewood case}

H.L., a man with autism, aged 48 years, had been in long-term care at Bournewood Hospital in Surrey before moving in with Mr and Mrs E. in 1994. They cared for him and treated him as one of their family. In July 1997, he became agitated while attending a day centre and was readmitted informally to Bournewood Hospital. Mr and Mrs E. disagreed with the admission and mounted a legal challenge in October 1997. The court ruled that H.L.'s 'informal' admission was illegal and that the Mental Health Act (MHA) 1983 should have been used. The Court of Appeal upheld this decision on 2 December 1997. The grounds for the ruling were that, although H.L. did not actively disagree with the admission, he lacked the capacity to do so

The House of Lords overturned the Court of Appeal's judgement, stating that it was against the liberal spirit of the MHA to automatically enforce detention if the patient lacks capacity 
in difficult or borderline situations. Many relatives need to be educated that the MHA can confer advantages to those detained (e.g. rights of appeal and after-care).

\section{Physical illness and old age psychiatry}

Older patients are more likely than the general population to have chronic physical ill health, and coexisting dementia can complicate treatment. However, as already stated, the present MHA operates solely for mental disorders. The term 'mental illness' is not defined in the MHA itself. Not all clinicians would agree that delirium qualifies as a mental illness. This stipulates that any impairment of intellectual function or mood should be 'more than temporary'. For these reasons, acute delirium is more appropriately managed under common law rather than under the MHA. Despite the sometimes uncomfortable vagueness of common law, it is the more appropriate legal safeguard for management of such cases.

\section{Public health}

As well as the MHA 1983, there is another scenario for compulsory management. Old age psychiatrists will be familiar with requests to assess someone living in a state of squalor - the ineptly named Diogenes syndrome. If the conditions are judged to be so unsanitary that they are a threat to public health, a community physician may invoke Section 47 of the National Assistance Act 1948 to have the person removed from his or her home. In fact, the majority of these people are elderly and would warrant admission to a psychiatric facility for assessment under Section 2 of the MHA (Wolfson et al, 1990). The National Assistance Act has been severely criticised for being an infringement of civil liberties, especially as there is no right of appeal. Furthermore, it remains to be seen what impact the Human Rights Act 1998 will have on its, albeit rare, use.

\section{Long-term care}

Many elderly people require long-term care but are unable to participate in the decision-making process. The legal framework for making these decisions in their interests is not perfect, which is disappointing, considering that they have profound long-term implications.

\section{Section 117}

First, it should be mentioned that Section 117 of the MHA imposes a duty on doctors and health authorities to provide suitable after-care for patients discharged from Section 3 (or, less commonly, Sections 37, 47 or 48). Interestingly, courts have been reluctant to force health authorities to provide aftercare even if, for example, a patient's discharge depends upon it. However, Section 117 is not only considered good practice but also implies a duty to provide funding for after-care. This obligation is not indefinite and a person treated under Section 117 can be 'discharged' by the responsible clinician once the situation seems stable (e.g. once a patient with dementia seems settled in a new nursing home) (Bartlett \& Sandland, 2000).

\section{Guardianship}

The area of the MHA most concerned with long-term care is Section 7, which provides for guardianship orders, under which a guardian is appointed with the following powers:

- to require the patient to reside at a place specified by the guardian

- to require the patient to attend at places and times specified for the purpose of medical treatment, occupation, education or training

- to require access to the patient to be given, at any place where the patient is residing, to any medical practitioner, approved social worker or other specified person.

The guardian is usually the local authority (represented by a senior social worker) or a relative. Adoctor's involvement would usually be to provide a medical recommendation, thereby prohibiting him or her from being the guardian. The place to reside is usually a nursing home, approved for this purpose under the MHA.

The operation of guardianship is similar to Section 3: two medical recommendations (one from a doctor approved under Section 12 of the MHA) are required plus an application from an approved social worker; the order lasts for 6 months in the first instance and carries similar rights of appeal. Doctors, who are used to making decisions on admission under Section 3 in the space of an hour or two, may be frustrated to find that colleagues in social services departments may take weeks or even months to reach a decision. Therefore, it is important to plan ahead if one suspects that guardianship is necessary. A good first step is to invite an approved social worker to a meeting convened to review the patient's care. 
Guardianship differs from a Section 3 in that it includes a number of provisions that serve only to confuse its purpose and implementation. The MHA Code of Practice (Mental Health Act Commission, 1999), for instance, states completely unrealistically that the patient must recognise the authority of the guardian, that access cannot be forced, that the patient may not be forcibly detained and that medical treatment cannot be administered without consent under guardianship (Bradshaw, 2002). One might ask what purpose guardianship then serves. The legislation is meant to be enabling and (unlike some other areas of the MHA) is clearly intended for patients who lack capacity, rather than for those who happen to have a psychiatric diagnosis and object to the plans. Even with this in mind, discussions on guardianship with non-medical colleagues may be confusing. The paradox of the guardian's 'authority' is that he or she has, in effect, to request the permission of the subject in order to exercise it. This matter can sometimes be addressed in difficult case conferences by pointing out that while patients may verbally refuse to recognise the 'authority' of the guardian, their actions contradict what they say. It is also reasonable to suggest that patients may need a period of time to adjust to the idea of guardianship. However, where problems persist, it may be necessary to admit to hospital under a Section of the MHA, to assess and develop a management strategy for patients whose behaviour repeatedly tests the guardianship. Some social workers prefer patients always to be admitted first to hospital under the MHA to smooth the way for guardianship. This can be useful, but is by no means obligatory; many would see a Section 3 as particularly inappropriate because it can be implemented only where community treatment is not thought possible. Clearly, this would not be the case if guardianship was already being planned.

Like Section 117 care plans, the concept of reciprocity is embedded in guardianship: guardians do not just exert power over individuals but are expected to be advocates on their behalf.

Since the Bournewood case, it might seem unnecessary to have specific legislation for those who lack capacity but are not objecting. Certainly, provision for long-term care is one area of the MHA that is ripe for reform under the new legislation being drafted.

\section{Financial matters}

Advancing age and diminished mental capacity have implications besides those of long-term care.
Several older patients now dispose of considerable assets, such as through their house, but have difficulty coping with complex financial matters. If individuals no longer have the capacity to manage their financial affairs, they fall within the jurisdiction of the Court of Protection. Elderly people with mental disorder constitute $70 \%$ of the Court's workload (Lush, 2002).

The Court of Protection rarely supervises a patient's finances directly; instead it appoints someone, the receiver, to undertake this under Part VII of the MHA.

\section{Enduring Power of Attorney Act 1985}

This is a legal device whereby individuals (donors or grantors) can designate another to manage their finances should they become mentally incapacitated. Usually, the attorney registers the Enduring Power of Attorney (EPA) with the Court of Protection only when the donor no longer has the mental capacity to manage financial affairs, when it becomes operative for the first time. The Court of Protection informs the donor and relatives in case they wish to appeal. Alternatively, an EPA can come into effect immediately it is signed and simply carries on should the donor subsequently lose capacity, although at this point the attorney is still obliged to register it with the Court of Protection.

The appointed person has the right and the responsibility to look after the donor's financial affairs and nothing else. For example, he or she has no right to make health care decisions on behalf of the donor. This is likely to change when the Government implements its White Paper on mental incapacity (Lord Chancellor's Department, 1997) and introduces a replacement for the EPA, to be called a Continuing Power of Attorney (CPA), which will permit proxy health care decisions to be made.

Obviously, it is important that the donor setting up the EPA has capacity to make such an important decision in the first place. The donor should be able to understand the following:

- that the attorney will have complete authority over the donor's affairs

- that the attorney can do anything with the donor's property that the donor could have done (attorneys are often relatives who are entitled to give themselves and others presents and money from the donor's estate if the donor has done this habitually)

- that the power will become effective when the donor becomes mentally incapacitated

- that the power cannot be revoked unless by the Court of Protection. 
In the light of the section on capacity above, the reader should realise that the donor has to be competent only to make this particular decision and not, in fact, necessarily competent to manage his or her financial affairs. Indeed, if someone who is competent to donate power of attorney but not competent to manage financial affairs does sign an EPA, then this must be registered straight away with the Court of Protection.

An EPA can be set up with a prescribed form; all that is required are the signatures of the donor, the proposed attorney and witnesses. In practice, it is advisable for the EPA to be drawn up by a lawyer and, where there is doubt as to the donor's capacity to give power of attorney, the donor should be examined by an old age psychiatrist.

The Court of Protection recommends that more than one attorney be appointed, to act 'jointly and severally' - meaning that they may act either together or individually - in case one falls ill or is unable to meet his or her duties. Attorneys can be appointed who have to make all decisions jointly, but this is cumbersome and is therefore discouraged.

\section{Court of Protection}

Not everyone will have drawn up an EPA. The usual course of action in this case is to have a receiver appointed by the Court of Protection itself, using procedures laid down in Part VII of the MHA.

The receiver is usually a member of the family who has made an application; less often it may be a lawyer or a representative of the local social services department. In rare cases, the court may feel it has no option but to appoint the public trustee, if no one else seems suitable.

To grant a Court of Protection Order, the court has to decide whether the patient has a mental disorder (as defined under the MHA) and whether he or she is incapable of managing his or her property and affairs. Unfortunately, the second criterion is not well defined and varies from one court judgement to another, but a useful guide is given by Silberfeld et al (1995).

The Court of Protection requires a certificate from a registered medical practitioner. Again, the patient is informed of the application - good reasons must be provided if the doctor believes that this would not be in the patient's best interests. If doubt remains over the medical recommendations, the court can ask one of its medical visitors to make an assessment.

The work of receivers is monitored; generally they have to submit accounts to the Court of Protection, as well as provide a sum of money to act as security that they will discharge their duties honestly. A receiver can manage any income from the patient's estate, but has to apply to the Court of Protection to use capital. The receiver, unless acting as a professional (e.g. accountant or solicitor), is not paid for his or her work.

The application process for receivership can take several months, and thereafter the receiver is under regular scrutiny by the Court of Protection. By contrast, an EPA is fairly easy to set up and the attorney has relative freedom of action, including the ability to dispose of the donor's capital, for example, selling a house. An EPA therefore provides greater choice for donor and attorney, but is more open to misuse.

The Public Guardianship Office, which oversees the Court of Protection, is a useful source of information on the EPA and receivership and can provide it in written form for doctors, patients and their families. For a more detailed discussion of the management of an incapacitated person's financial affairs, see Lush (2002).

\section{Drawing up a will}

The drafting and signing of a will requires the patient to show 'testamentary capacity'. The criteria for testamentary capacity go back to the case of Banks v. Goodfellow (1870) and differ somewhat from the more general concept of mental capacity discussed above. English law is drafted in a variety of circumstances, which leads to different tests for the legal concept of capacity. However, a careful comparison of Boxes 1 and 3 will reveal more similarities than at first sight.

'Understanding the nature of the will' means testators understand that they are giving their property to one or more objects of their regard. Testators are not required to have an exact knowledge of their estate, but should have an idea of what form

\section{Box 3 Testamentary capacity}

The testator (the person drawing up the will) must:

1 understand the nature of the act and its effects

2 understand the extent of the property of which he or she is disposing

3 understand the nature and extent of the claims on him or her, both of those whom he or she is including in the will and of those excluded

4 have no mental disorder directly affecting 1-3 above

5 not be subject to undue influence by one or more third parties 
their property takes and in what proportions. They should also be aware of any debts, joint ownerships and who benefits from which investment. It follows that the more complex the estate, the greater the degree of testamentary capacity required.

In order to prove that the contents of a will have been influenced by mental disorder, it is important to demonstrate not only that there was a specific mental disorder present, but also that it affected the criteria for testamentary capacity outlined in Box 2 . It is not enough to say that the will was unfair, malicious or capricious, nor is it enough to prove that someone was mentally ill when the will was drawn up. It must be proved that the illness had a direct effect on the criteria for testamentary capacity. Undue influence by third parties is extremely difficult to prove.

Some time may elapse between giving instructions for a will and its execution (signing in front of witnesses). It is desirable that testators have testamentary capacity on both occasions, but the exact requirements vary: they must have full capacity when they gives the instructions, but when they comes to execute the will, it may be sufficient for them simply to know that they are signing a will drawn up on their instructions.

Doctors asked to assess a person's testamentary capacity need to be aware of both the legal and the medical issues. They should:

- examine the patient specifically in relation to the Banks v. Goodfellow criteria

- make contemporaneous notes of the examination and record the reasons for their conclusions.

Doctors may also become embroiled in issues of testamentary capacity after the testator's death when parties who did not stand to inherit contest the will. A doctor will either be involved as a medical practitioner who knew the patient (a witness as to fact), or as an expert witness trying to piece together, in retrospect, the evidence relating to the patient's capacity. The importance of clear and comprehensive medical notes cannot be overemphasised for such cases.

Anyone thinking of contesting a will should be aware that the legal costs could exceed the value of the estate and are, in any case, likely to be very high. For a more detailed discussion of testamentary capacity, see Posener \& Jacoby (2002).

\section{Driving}

For older patients, driving may be one of the last vestiges of independence, which can be difficult to relinquish, particularly if they lack insight, as in dementia. It can be awkward to broach the subject. Some clinicians find it helpful to say that a diagnosis of dementia will affect the ability to obtain motoring insurance and use this as an avenue into discussions. If patients are not receptive, they might be encouraged at least to contact the Driver and Vehicle Licensing Authority (DVLA), with the assurance that the DVLA will not leap to conclusions but simply make some exploratory enquiries (in the shape of forms to be filled in by the patient and doctor). Patients who insist that there is nothing wrong might be persuaded to attend a driving assessment centre. If the patient cannot be persuaded, then the doctor should contact the DVLA if he or she considers that the risks to the public outweigh the duty of confidentiality, in which case it is good practice to inform the patient and, of course, the general practitioner.

Younger clinicians often make assumptions about their older patients' ability to drive. They should bear in mind that the elderly are statistically at low risk of accidents, probably because they compensate for any cognitive defects by driving more carefully and avoiding difficult situations such as driving at night. The DVLA is less interested in minor cognitive impairment than we might suppose and more interested in actual ability to drive (O'Neill, 2002).

\section{Human Rights Act 1998 and future legislation}

In autumn 2000, the Human Rights Act 1998 came into force. The aim was to bring UK law into line with the European Convention on Human Rights. Existing laws in the UK may be challenged if they contravene the principles set out in the new Act, but it is too early to say what impact this will have in areas such as mental health.

The Government has promised a comprehensive review of mental health law, citing the need to bring existing legislation into line with the European Convention on Human Rights. Some of the proposed legislation is controversial, and fears have been expressed by the Royal College of Psychiatrists that some of the Government's proposals may lead to more rather than less conflict with the European Convention on Human Rights (see http//www. rcpsych.ac.uk/college/parliament/wp.htm).

The department of Health's (1999) Green Paper on reforming the MHA 1983 has sought to widen the scope for detention and treatment. There will now be a definition of mental disorder, which may include personality disorder, brain injury and 
learning disability. It is possible that grounds for detention may be based on the patient's capacity to understand his or her illness and need for treatment (reflecting the scoping group's recommendations), although the Government has indicated that it prefers risk to the public as a criterion for detention.

The Law Commission issued a report entitled Mental Incapacity in 1995, which was itself based on a number of consultation papers issued between 1991 and 1993. For a list of these, see Who Decides? (Lord Chancellor's Department, 1997). As a result of this consultation, the Government has declared its intention, in a document entitled Making Decisions (Lord Chancellor's Department, 1999), to introduce new legislation, but at the time of writing no bill has been published and parliamentary time for it has not yet been allocated. The main proposals include reform of the Court of Protection and introduction of the new CPA (see above).

\section{Living wills/advance directives}

These are almost invariably refusals of medical treatment. For example, 'If I develop Alzheimer's disease such that I am incontinent, not fully aware of my surroundings and do not recognise my family, I should not be given any treatment that could prolong my life.' One major objection to advance directives is that the people who make them cannot possibly envisage all the situations that might arise in the future. For example, if a woman making the directive above were to develop a large bowel obstruction, would she prefer to burst her bowel and have a rather horrible death sooner, or have a relieving operation and fade away more comfortably? At present, advance directives are not enshrined in statute law but do have force in common law. Thus, as a general rule, clinicians should adhere to them (Fazel, 2002).

\section{Conclusion}

It is difficult to summarise such a disparate area of practice, but a few general principles can be reiterated. By and large, the law does not treat older people any differently from the general adult population. However, life changes and social situation may mean that the elderly have greater need of protection from existing laws. The presence of mental illness underscores that vulnerability, particularly as elderly people are more at risk of conditions such as delirium or dementia, which can

\section{Box 4 Websites and useful contacts}

DVLA, Longview Road, Swansea SA6 7JL. Website: http:/ / www.dvla.gov.uk

Mental Health Act Commission, Maid Marian House, 56 Houndsgate, Nottingham NG1 6BG. Tel: 01159437100

Office of Care and Protection (Northern Irish version of Public Trust Office), Royal Courts of Justice, Chichester Street, Belfast BT1 3JF. Tel: 02890235111

Office of the Public Guardian, Hadrian House, Callender Business Park, Callender Road, Falkirk FK1 1XR. Tel: 01324678300

Office of Wards of Court, Aras Ui Dhalaigh, 3rd Floor, 15/24 Phoenix Street North, Smithfield, Dublin 7. Tel: +353 (0) 1888 $6189 / 6140$

Public Guardianship Office, Archway Tower, 2 Junction Road, London N19 5SZ. Tel: 020 76647000

Supreme Court, Accountant of the Court, Parliament Square, Edinburgh EH1 1RQ. Tel: 01312252595

http:/ / www.markwalton.net

http:/ / www.parliament.the-stationery-office. co.uk/cgi-bin/empower (the House of Lords has published every ruling since 1996 on the internet)

rob them of the capacity to make important decisions. Perhaps issues relating to capacity, finance and long-term care should be considered more often in younger adults with mental illnesses. In either case, good liaison, communication and record-keeping are essential for any psychiatrist considering legal issues where his or her patients are concerned.

\section{References}

Arie, T. (1996) Some legal aspects of mental capacity. BMJ 313, 156-158.

Bartlett, P. \& Sandland, R. (2000) Mental Health Law: Policy and Practice. London: Blackstone.

Bradshaw, M. (2002) Clinical practice: social work with older persons. In Psychiatry in the Elderly (3rd edn) (eds R. Jacoby \& C. Oppenheimer), pp. 315-332. Oxford: Oxford University Press.

British Medical Association \& Law Society (1995) Assessment of Mental Capacity: Guidance for Doctors and Lawyers. London: British Medical Association.

Department of Health (1999) Reform of the Mental Health Act 1983: Proposals for Consultation. Cm 4480. London: Stationery Office.

_ (2001) Reference Guide to Consent for Examination or Treatment. London: Department of Health.

Fazel, S. (2002) Competence. In Psychiatry in the Elderly (3rd edn) (eds R. Jacoby \& C. Oppenheimer), pp. 941-950. Oxford: Oxford University Press. 
Kearney, N. \& Treloar, A. (2000) In the light of Bournewood: changes in the management of elderly incapacitated patients. Psychiatric Bulletin, 24, 52-54.

Law Commission (1997) Mental Incapacity. LC 231. London: Stationery Office.

Lord Chancellor's Department (1997) Who Decides: Making Decisions on behalf of Mentally Incapacitated Adults. Cm 3803. London: Stationery Office.

— (1999) Making Decisions: The Government's proposals for Making Decisions on behalf of Mentally Incapacitated Adults. Cm 4465. London: Stationery Office.

Lush, D. (2002) Managing the financial affairs of mentally incapacitated persons in the United Kingdom and Ireland. In Psychiatry in the Elderly (3rd edn) (eds R. Jacoby \& C. Oppenheimer), pp. 951-965. Oxford: Oxford University Press.

Mental Health Act Commission (1999) Code of Practice to the Mental Health Act 1983. London: HMSO.

O'Neill, D. (2002) Driving and psychiatric illness in later life. In Psychiatry in the Elderly (3rd edn) (eds R. Jacoby \& C. Oppenheimer), pp. 966-976. Oxford: Oxford University Press.

Posener, H. D. \& Jacoby, R. (2002) Testamentary capacity. In Psychiatry in the Elderly (3rd edn) (eds R. Jacoby \& C. Oppenheimer), pp. 932-940. Oxford: Oxford University Press.

Silberfeld, M., Corber, W., Madigan, K. V., et al (1995) Capacity assessments for requests to restore legal competence. International Journal of Geriatric Psychiatry, 10, 191-197.

Wolfson, P., Cohen, M., Lindesay, J., et al (1990). Section 47 and its use with mentally disordered people. Journal of Public Health Medicine, 12, 9-14.

Banks v Goodfellow [1870] LR 5 QB 549.

Bolam v Governors of Friern Hospital [1957] 1 WLR 582.

$R v$ Bournewood Community and Mental Health NHS Trust, ex parte L [1998] 3 AllER 298, London.

\section{Multiple choice questions}

1. To have capacity to make a decision, a person must:

a show understanding of all significant information

$\mathrm{b}$ retain all information indefinitely

c make the decision free from undue pressure

d not be detained under the MHA 1983

e must consider the consequences of the decision.

2. Regarding legal procedures for admission to, and treatment in, hospital:

a patients who lack capacity must be admitted under the MHA

$\mathrm{b}$ the Bournewood case has led to a major revision of UK mental health law

c the National Assistance Act (1948) is now rarely used

d Section 5(2) of the MHA can be used if there is doubt about capacity, to treat a medical emergency

e Section 117 of the MHA can be used to give treatment against consent after discharge.

3. As regards guardianship:

a application for guardianship requires the agreement of two doctors (one Section 12 approved) and an approved social worker

b procedures for guardianship are usually completed within a few hours

c one of the doctors recommending guardianship can become the guardian

$\mathrm{d}$ the guardian can require the subject to give access to a medical doctor

e guardianship is principally intended to allow out-patient treatment against the subject's wishes.

4. The following statements are true regarding the Court of Protection:

a elderly people with mental disorder account for $70 \%$ of its work

$\mathrm{b}$ the Court of Protection has jurisdiction over both EPA and MHA Part VII work

c the Public Guardianship Office provides written information on Court of Protection work

d individuals can sign an EPA only while they still have the mental capacity to look after their financial affairs

e people appointed as attorneys under an EPA can, under certain circumstances, give themselves gifts from the donor's estate.

5. Regarding making a will:

a the usual criteria for capacity do not apply to drawing up a will, which has its own specific tests for capacity

$\mathrm{b}$ any will drawn up when the testator was mentally ill automatically becomes invalid

$c$ the execution (signing) of a will requires exactly the same level of capacity in the testator as when he or she gave instructions for the will to be drawn up

$\mathrm{d}$ a will can be successfully contested if it is regarded as capricious

e the cost of contesting a will can exceed those of the estate contested.

\section{MCQ answers}

\begin{tabular}{|c|c|c|c|c|}
\hline 1 & 2 & 3 & 4 & \\
\hline a $T$ & a $F$ & a $\mathrm{T}$ & & $\mathbf{T}$ \\
\hline b $\mathbf{F}$ & b F & b F & b & $\mathbf{T}$ \\
\hline c $T$ & c $\mathrm{T}$ & c F & c & $\mathbf{T}$ \\
\hline d F & d F & d $\mathbf{T}$ & & $\mathbf{F}$ \\
\hline e $T$ & e $F$ & e $F$ & e & $\mathbf{T}$ \\
\hline
\end{tabular}

